\title{
Comparison of ED95 of Butorphanol and Sufentanil for gastrointestinal endoscopy sedation: a randomized controlled trial
}

\author{
Xiaona Zhu, Limei Chen, Shuang Zheng and Linmin Pan ${ }^{*}$ (1)
}

\begin{abstract}
Background: Butorphanol, a synthetic opioid partial agonist analgesic, has been widely used to control perioperative pain. However, the ideal dose and availability of butorphanol for gastrointestinal (GI) endoscopy are not well known. The aim of this study was to evaluated the $95 \%$ effective dose $\left(E D_{95}\right)$ of butorphanol and sufentanil in Gl endoscopy and compared their clinical efficacy, especially regarding the recovery time.

Methods: The study was divided into two parts. For the first part, voluntary patients who needed Gl endoscopy anesthesia were recruited to measure the $\mathrm{ED}_{95}$ of butorphanol and sufentanil needed to achieve successful sedation before Gl endoscopy using the sequential method (the Dixon up-and-down method). The second part was a double-blind, randomized study. Two hundred cases of painless Gl endoscopy patients were randomly divided into two groups $\left(n=100\right.$ ), including group $B$ (butorphanol at the $\mathrm{ED}_{95}$ dose) and group $\mathrm{S}$ (sufentanil at the $\mathrm{ED}_{95}$ dose). Propofol was infused intravenously as the sedative in both groups. The recovery time, visual analogue scale (VAS) score, hand grip strength, fatigue severity scores, incidence of nausea and vomiting, and incidence of dizziness were recorded.
\end{abstract}

Results: The $\mathrm{ED}_{95}$ of butorphanol for painless $\mathrm{Gl}$ endoscopy was $9.07 \mu \mathrm{g} / \mathrm{kg}$ (95\% confidence interval: 7.81 $19.66 \mathrm{\mu g} / \mathrm{kg})$. The $\mathrm{ED}_{95}$ of sufentanil was $0.1 \mu \mathrm{g} / \mathrm{kg}(95 \% \mathrm{Cl}, 0.079-0.422 \mu \mathrm{g} / \mathrm{kg})$. Both butorphanol and sufentanil provided a good analgesic effect for $\mathrm{Gl}$ endoscopy. However, the recovery time for butorphanol was significantly shorter than that for sufentanil ( $P<0.05$, group B vs. group S:21.26 \pm 7.70 vs. $24.03 \pm 7.80 \mathrm{~min}$ ).

Conclusions: Butorphanol at $9.07 \mu \mathrm{g} / \mathrm{kg}$ was more effective than sufentanil for $\mathrm{Gl}$ endoscopy sedation and notably reduced the recovery time.

Trial registration: Chinese Clinical Trail Registry (Registration number \# ChiCTR1900022780; Date of Registration on April 25rd, 2019).

Keywords: Butorphanol, Sufentanil, Gastrointestinal endoscopy, Sedation

\section{Background}

The morbidity from gastric and intestinal cancer is ranked second and fifth highest for cancers in China, respectively [1]. Gastrointestinal (GI) examination has

\footnotetext{
*Correspondence: panlinmina@163.com

Department of Anesthesiology, the First Affiliated Hospital, Wenzhou Medical University, Shangcai village, Nanbaixiang town, Ouhai District, Wenzhou City 325000, Zhejiang Province, China
}

been used as a standard method for the diagnosis of esophageal, gastroduodenal, and colorectal disease. However, unbearable abdominal pain can be caused by the distension and traction of viscera during GI endoscopy, eventually resulting in poor conditions for observation and severe arrhythmia [2]. Presently, sedative drugs combined with analgesics are typically used to alleviate pain and nervousness during GI endoscopy.

C C The Author(s). 2020 Open Access This article is licensed under a Creative Commons Attribution 4.0 International License, which permits use, sharing, adaptation, distribution and reproduction in any medium or format, as long as you give appropriate credit to the original author(s) and the source, provide a link to the Creative Commons licence, and indicate if changes were made. The images or other third party material in this article are included in the article's Creative Commons. licence, unless indicated otherwise in a credit line to the material. If material is not included in the article's Creative Commons licence and your intended use is not permitted by statutory regulation or exceeds the permitted use, you will need to obtain permission directly from the copyright holder. To view a copy of this licence, visit http://creativecommons.org/licenses/by/4.0/ The Creative Commons Public Domain Dedication waiver (http://creativecommons.org/publicdomain/zero/1.0/) applies to the data made available in this article, unless otherwise stated in a credit line to the data. 
Currently, opioid $\mu$ receptor agonists, such as sufentanil and fentanyl, are the most commonly used analgesics. The stomach and intestine are mainly innervated by the sympathetic and parasympathetic nervous systems [3] and the kappa receptor agonist is found at higher concentrations in the spinal cord thus is involved in relieving visceral pain [4]. Butorphanol is a kappa receptor agonist, which has the advantages of light respiratory depression, stable hemodynamics, a rapid onset, and a moderate effective duration [5], and it may be a more suitable intraoperative and postoperative analgesic for painless GI endoscopy.

Butorphanol is a more effective analgesic than morphine, while its respiratory depression is as low as $1 / 5$ that of morphine [6]. At present, butorphanol can be safely applied as a maternal analgesic, especially for pregnant women with pre-eclampsia and chronic hypertension, it dose not cause severe fluctuations in blood pressure [7]. Butorphanol has also been used in outpatients undergoing laparoscopic tubal sterilization in the early stage [8], although the analgesic dose has not been standardized $[9,10]$. It is imperative that the optimal butorphanol dose that produces analgesia and minimizes side effects during outpatient sedation is found.

The objective of this study was to detect the $\mathrm{ED}_{50}$, $\mathrm{ED}_{95}$, and $95 \%$ confidence intervals for butorphanol using the sequential method and to compared these to the $\mathrm{ED}_{95}$ dose of sufentanil to assess the feasibility and superiority of butorphanol in GI endoscopy.

\section{Methods}

This clinical study was approved by the Hospital Ethics Committee of the First Affiliated Hospital of Wenzhou Medical University and was registered in the Clinical Trial Registration Center of China (ChiCTR1900022780). Informed consent was obtained from all individual participants included in the study. This study adhered to CONSORT guidelines.

This study was based on the medical records of ASA I-II patients aged 18 to 65 who underwent an outpatient GI endoscopy (diagnostic esophagogastroduodenoscopy and colonoscopy, without therapeutic procedures), who required anesthesia and an operation of no more than $30 \mathrm{~min}$ in duration at the endoscopy center from May to July 2019. Patients were excluded from the study based on the following criteria: not willing or able to finish the whole study; acute upper respiratory tract infection; hepatitis and renal failure; habitual sedative or analgesic use; analgesic use for acute pain; chronic fatigue syndrome; low potassium; myasthenia gravis; psychiatric disease; and allergy to butorphanol, sufentanil, or propofol.

This study was divided into two parts: (1) determination of the $\mathrm{ED}_{95}$ of butorphanol and sufentanil; (2) comparison of the clinical efficacy of butorphanol with the efficacy of the equivalent sufentanil.

\section{$\mathrm{ED}_{95}$ of butorphanol and sufentanil}

All patients underwent routine GI preparation before endoscopy, fasting from solids for $8 \mathrm{~h}$ and liquids for $2 \mathrm{~h}$ before the operation. The anesthesia machine was inspected, and intravenous access was established. Before inducting anesthesia in the outpatient operating room, standard monitoring was applied, including for noninvasive blood pressure (BP), electrocardiogram (ECG), and oxygen saturation $\left(\mathrm{SpO}_{2}\right)$, and the patients were placed in the left lateral position. All the patients received $3 \mathrm{~L}$ per minute supplemental oxygen via nasal inhalation and were asked to hold the facial mask themselves.

Butorphanol (Batch number: 190411BP, Jiangsu Hengrui Pharmaceutical Co., Ltd.) or sufentanil (Batch number: 3018511505, Yichang Humanwell Pharmaceutical Co., Ltd.) was slowly injected intravenously. Given the 3 min onset time, propofol (Batch number: 1811236 Beijing Fresenius Kabi Pharmaceutical Co., Ltd.) was administrated intravenously at a constant speed until the patient lost consciousness and dropped the hand-held mask, followed by a continuous intravenous infusion at a rate of $50-150 \mu \mathrm{g} \cdot \mathrm{kg}^{-1} \cdot \mathrm{min}^{-1}$. The bispectral index (BIS) was monitored (BIS Complete Monitoring System, Covidien), and a controlled BIS value of between 50 and 60 was maintained by adjusting propofol speed. Then, the endoscopy was begun (operated by the same gastroenterologist). If the patient showed "failed sedation" (definition of failed sedation: occurrence of gag reflex [11], coughing, or body movement during esophagogastroduodenoscopy, or body movement during colonoscopy) during the GI endoscopy, an additional propofol dose of $0.5-1 \mathrm{mg} / \mathrm{kg}$ was administered. Once the $\mathrm{SpO}_{2}$ fell to $90 \%$, assisted ventilation with oxygen via a facial mask was applied. If the heart rate dropped below 45 beats per minute, atropine $(0.5 \mathrm{mg})$ was applied. If the mean arterial pressure was less than $50 \mathrm{mmHg}$, ephedrine 5-10 mg was administered. After surgery, the patients were transported to the postanesthesia care unit (PACU) to rest and recover.

\section{Dixon up-and-down method}

The dose of butorphanol administered to each patient was determined by the Dixon up-and-down method [12]. According to geometric progression, the dose gradient was divided into six steps: 12.00, 10.00, 8.33, 6.94, 5.79 , and $4.82 \mu \mathrm{g} / \mathrm{kg}$. In a preliminary experiment, the $\mathrm{ED}_{95}$ of butorphanol for "successful sedation" (definition of successful sedation: without gag reflex, coughing, or body movement in esophagogastroduodenoscopy and body movement in colonoscopy) with propofol in 
outpatient GI endoscopy was $9.8 \mu \mathrm{g} / \mathrm{kg}$. Therefore, the first patient was prescribed a dose of $10.00 \mu \mathrm{g} / \mathrm{kg}$. The dose grade was increased or decreased using the updown method based on the failure or success of the sedation in the previous patient. This process was repeated until there were nine cross-over pairs [13] (i.e., one successful sedation, followed by one failed sedation).

The dose of sufentanil given to each patient was also determined by the Dixon up-and-down method. According to geometric progression, the dose gradient was divided into six steps: 0.12, 0.1, 0.083, 0.069, 0.058, and $0.048 \mu \mathrm{g} / \mathrm{kg}$. In the preliminary experiment, the $\mathrm{ED}_{95}$ of sufentanil for "successful sedation" with propofol in outpatient GI endoscopy was $0.085 \mu \mathrm{g} / \mathrm{kg}$. Thus, the first patient was prescribed a dose of $0.083 \mu \mathrm{g} / \mathrm{kg}$. The following process was similar to that used for testing the $\mathrm{ED}_{95}$ of butorphanol.

\section{Comparison with sufentanil Groups}

Two hundred cases of painless GI endoscopy patients were recruited. The patients were randomly divided into two groups: the butorphanol group (group B, $n=100$ ) and the sufentanil group (group S, $\mathrm{n}=100$ ).

\section{Anesthesia methods}

This part of the study was double-blind and randomized. The patients were grouped according to the envelope method. The dispensing nurse dispensed the drugs according to the directions of the anesthetist. The preoperative preparation and anesthesia methods were the same as in the first part of the study and were performed by the anesthetist. The $\mathrm{ED}_{95}$ dose of butorphanol $(9.07 \mu \mathrm{g} / \mathrm{kg})$ was administered to group B. The $\mathrm{ED}_{95}$ doses of sufentanil $(0.1 \mu \mathrm{g} / \mathrm{kg})$ was administered to group $\mathrm{S}$. The $\mathrm{ED}_{95}$ doses of butorphanol and sufentanil were estimated in the first part of the study. Postoperative indications in the PACU were evaluated and recorded by another postoperative observer who was blinded to the group division.

\section{Efficacy measurements and variables}

The primary outcome in this study was the recovery time, which represented the time from completion of the examination and to the patient's departure from the PACU. The standards for hospital discharge were our outpatient operational standards [14] (including vital signs, pain, orientation, dizziness, and walking). The secondary outcomes included the demographic and medical data, i.e., the incidence of respiratory depression (respiratory rate $<10$ beats/min or $\mathrm{SpO}_{2}<90 \%$ in nasal catheter oxygenation with $3 \mathrm{~L} / \mathrm{min}$ ), the incidence of circulatory inhibition (MAP $<50 \mathrm{mmHg}$ or $\mathrm{HR}<45$ beats $/ \mathrm{min})$, dosage of propofol, the incidence of failed sedation, fatigue severity scores (assessed with an 11point (0-10) scale [15] $15 \mathrm{~min}$ after awakening time), VAS score of abdominal pain ( $15 \mathrm{~min}$ after awakening time), value of hand grip strength before and $15 \mathrm{~min}$ after operation (assessed using an electronic hand dynamometer [EH101, Camry Co. Zhongshan, China]), the incidence of nausea and vomiting, and dizziness after awakening.

\section{Statistical analysis}

SPSS statistical software (IBM Corporation, version 19) was used for statistical analyses. The median effective dose $\left(E_{50}\right), E D_{95}$, and the $95 \%$ confidence intervals $(\mathrm{CI})$ of butorphanol and sufentanil were determined by binary regression (probit) [16].

The sample size in part two was evaluated by PASS 11.0. The primary indicator was recovery time. The preexperimental measurements showed that the recovery time was $22.12 \pm 7.9 \mathrm{~min}$ in the butorphanol group and $25.57 \pm 8.1 \mathrm{~min}$ in the sufentanil group. A sample size of 93 in each group was determined to be required for a $\beta$ value of 0.10 and an $\alpha$ value of 0.05 . Considering the loss of data and the number of patients who could not be interviewed after endoscopy, 100 patients were selected in each group to ensure that the experiment had a large enough sample size.

Normally distributed data were analyzed with the mean \pm standard deviation, and a two independent sample $t$-test was used to evaluate the differences between the two groups. The non-parametric data were analysed using the median (Q1, Q3) or ratio, and a nonparametric test was used to evaluate the differences between the two groups. The complication rates were compared using a four-square table Chi-squared test. A $P$-value $<0.05$ was considered to be statistically significant.

\section{Results}

The data of 30 patients were screened in the first part of the study. One patient was excluded due to poor GI preparation, thus 29 cases remained. The individual responses to butorphanol assessed using Dixon's up-and-down method are shown in Fig. 1. The $\mathrm{ED}_{50}$ of butorphanol for inhibiting body movement during painless GI endoscopy was $6.58 \mu \mathrm{g} / \mathrm{kg}(95 \% \mathrm{CI}, 5.57-7.49 \mu \mathrm{g} / \mathrm{kg})$, and the $\mathrm{ED}_{95}$ of butorphanol was $9.07 \mu \mathrm{g} / \mathrm{kg}$ (95\% CI, $7.81-19.66 \mu \mathrm{g} / \mathrm{kg}$ ) for the same procedure. A total of 37 patients were included in the second part of the study. The individual responses to sufentanil assessed using Dixon's up-and-down method are shown in Fig. 2. The $\mathrm{ED}_{50}$ of sufentanil for inhibiting body movement during painless GI endoscopy was $0.060 \mu \mathrm{g} / \mathrm{kg}$ (95\% CI, $0.048-0.073 \mu \mathrm{g} / \mathrm{kg})$ and the $\mathrm{ED}_{95}$ of sufentanil was $0.100 \mu \mathrm{g} / \mathrm{kg}$ (95\% CI, 0.079 $0.422 \mu \mathrm{g} / \mathrm{kg}$ ) for the same procedure. No significant 


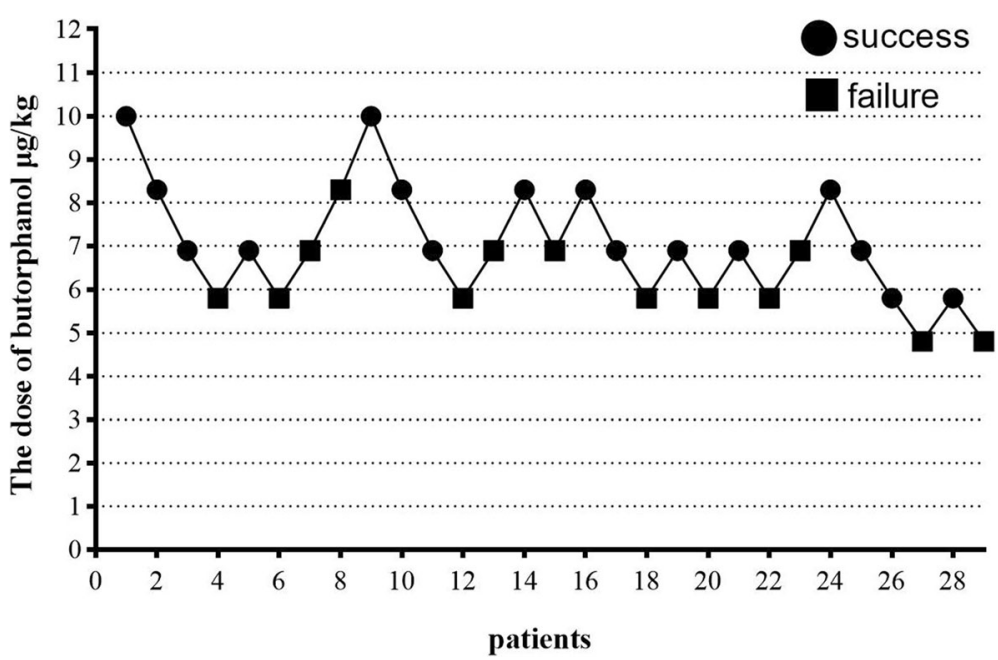

Fig. 1 Responses (successful sedation) of 29 consecutive patients who received butorphanol as an analgesic during Gl endoscopy

circulatory or respiratory depression occurred during the operation.

A total of 200 patients were recruited to completed the second part of the study, and their data were analyzed to produce the final results ( $n=100$ per group). The characteristics of the enrolled subjects are shown in Table 1. There were no significant differences between the two groups regarding patient age-gender composition, SBP (Systolic Blood Pressure), heart rate, weight, height, BMI, GI endoscopy operation time, preoperative hand grip strength, and ASA (American Society of Anesthesiologists) grade composition $(P>0.05)$.

There were no statistically significant differences in the incidences of respiratory depression $(P=0.469)$, circulatory inhibition $(P=0.489)$, failed sedation $(P=0.352)$, dizziness $(P=0.205)$, and propofol dosage $(P=0.171)$. Compared to group $\mathrm{S}$, group $\mathrm{B}$ showed lower fatigue severity scores $(P=0.001)$ and better postoperative hand grip strength $(P<0.001)$. Furthermore, the recovery time for group $B$ was significantly shorter than for group $S$ $(P=0.012)$. The incidence of nausea and vomiting for group $\mathrm{B}$ was significantly lower than for group $\mathrm{S}(P=$ 0.014), as shown in Table 2.

\section{Discussion}

In our study, the $\mathrm{ED}_{50}$ of butorphanol for inhibiting body movement in painless GI endoscopy was $6.58 \mu \mathrm{g} /$ $\mathrm{kg},(95 \% \mathrm{CI}: 5.57-7.49 \mu \mathrm{g} / \mathrm{kg})$ and the $\mathrm{ED}_{95}$ was $9.07 \mu \mathrm{g} /$ $\mathrm{kg}(95 \% \mathrm{CI}: 7.81-19.66 \mu \mathrm{g} / \mathrm{kg})$. The $\mathrm{ED}_{50}$ for inhibiting body movement of sufentanil in painless GI endoscopy

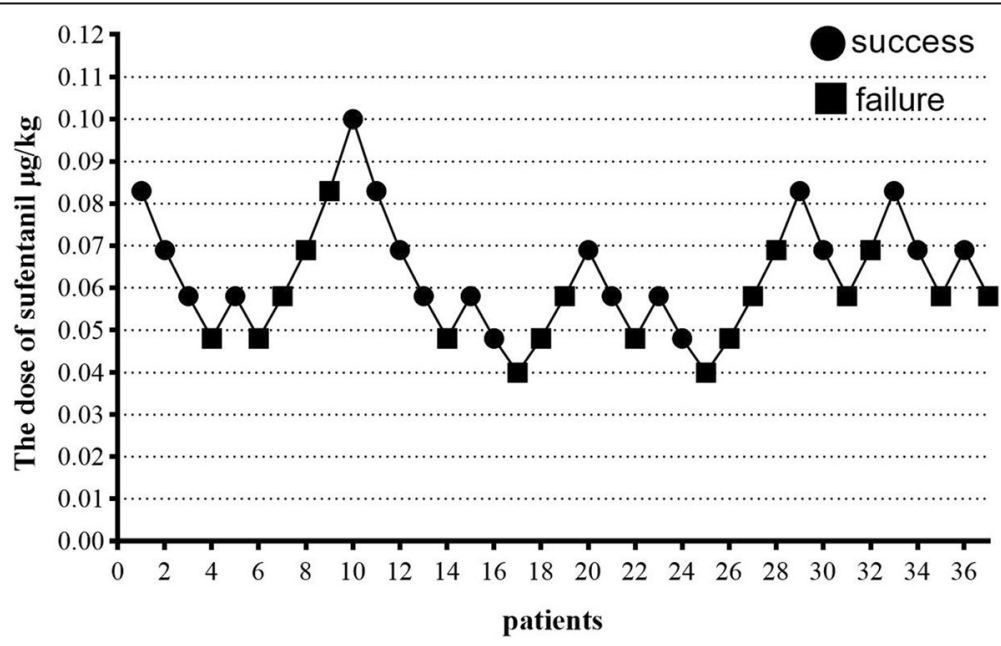

Fig. 2 Responses (successful sedation) of 37 consecutive patients who received sufentanil as an analgesic during Gl endoscopy 
Table 1 General comparison between group S and group B

\begin{tabular}{lll}
\hline & S group $(n=100)$ & B group $(n=100)$ \\
\hline Weight, kg & $63 \pm 11$ & $64 \pm 10$ \\
Sex (male, female) & $(60,40)$ & $(63,37)$ \\
SBP, mmHg & $128 \pm 15$ & $130 \pm 21$ \\
Heat rate, beats/min & $69 \pm 17$ & $77 \pm 13$ \\
Height, cm & $165 \pm 8$ & $166 \pm 8$ \\
BMl, kg/m ${ }^{2}$ & $23.3 \pm 3.0$ & $23.4 \pm 2.8$ \\
Operation time, min & $14.4 \pm 4.9$ & $14.6 \pm 4.9$ \\
Preoperative hand grip strength, kg & $42.9 \pm 9.5$ & $44.4 \pm 8.9$ \\
ASA classification, l/ll & $60 / 40$ & $66 / 34$ \\
\hline
\end{tabular}

ASA American Society of Anesthesiologists ASA physical status classification. Normally distributed statistics dates were mean $\pm S D$, and a two independent sample $\mathrm{t}$-test was used to evaluate the differences between the two groups. Sex and ASA classification were ratio and were compared by $x 2$ test. There were no significant differences between the two groups $(P>0.05)$

was $0.060 \mu \mathrm{g} / \mathrm{kg}(95 \% \mathrm{CI}, 0.048-0.073 \mu \mathrm{g} / \mathrm{kg})$ and the $\mathrm{ED}_{95}$ was $0.100 \mu \mathrm{g} / \mathrm{kg}$ (95\% CI, $\left.0.079-0.422 \mu \mathrm{g} / \mathrm{kg}\right)$. In the second part of our study, the primary indicator (recovery time) in group B was significantly shorter than that in group S. Compared to group S, the VAS score, fatigue severity score, incidence of postoperative nausea and vomiting were lower in group B.

A sequential method was used to accurately select the optimal doses of butorphanol and sufentanil for GI endoscopy. An advantage of this method is that it can be used to evaluate the efficacy of drugs using fewer cases over a short time. The $\mathrm{ED}_{95}$ values of butorphanol and sufentanil were $9.07 \mu \mathrm{g} / \mathrm{kg}$ and $0.1 \mu \mathrm{g} / \mathrm{kg}$, respectively, which were close to the doses used in the first patients in whom we administered the drugs $(10$ and $0.83 \mu \mathrm{g} / \mathrm{kg}$, respectively). In our study, we confirmed that there was no difference in the incidences of successful sedation using the $\mathrm{ED}_{95}$ of butorphanol and sufentanil during GI endoscopy.
With a published in vitro affinity for opioid receptors of 1:4:25 (mu: delta: kappa), butorphanol has been known to act on kappa-opioid receptors of the upper spinal cord to inhibit nociceptive stimulus conduction [5]. Ozaki et al. demonstrated that kappa-, but not muor delta-, opioid receptor agonists modulate visceral sensations conveyed by the vagal afferent fibers innervating the stomach [17]. Soichiro et al. reported that butorphanol-induced visceral chemical antinociception was entirely blocked by pretreatment with a kappaopioid receptor antagonist [18]. Kappa receptor shows absent related to respiratory depression, nausea, and vomiting. The mu receptor has strong effects on respiratory depression and is associated with nausea and vomiting [19]. Our experimental results are consistent with previous findings; they also confirm that butorphanol is less likely to cause nausea and vomiting and show that butorphanol resulted in a lower postoperative VAS score than the pure mu-opioid receptor agonist sufentanil at the $\mathrm{ED}_{95}$ dose. The most likely reason for this is the difference between the kappa and mu receptors. In addition, the doses of butorphanol and sufentanil used in our study were low, thus led to a low incidence of respiratory depression and did not result in a significant difference between them. The duration of the analgesic effect of butorphanol is about $4 \mathrm{~h}$. Although the average examination time of painless GI endoscopy is not that long, the patient still needs excellent analgesia after waking up. PremyslFalt et al. reported that, with an intravenous injection of $2 \mathrm{mg}$ midazolam after routine air-inflated GI endoscopy, $1 \%$ of patients still reported abdominal pain and $2 \%$ of patients had flatulence during the $3 \mathrm{~h}$ and $30 \mathrm{~min}$ after the procedure had finished [20]. It is essential to have excellent analgesia during this period, and butorphanol is a suitable choice.

Postoperative fatigue influences the emotional and mental state of the patients after surgery and affects

Table 2 Comparison of the indicators between group $\mathrm{S}$ and group B

\begin{tabular}{llll}
\hline & S group $(\mathrm{n}=100)$ & B group $(n=100)$ & $P$ value \\
\hline Incidence of respiratory depression & $11 \%$ & $8 \%$ & 0.469 \\
Incidence of circulatory inhibition & $12 \%$ & $9 \%$ & 0.489 \\
Dosage of propofol, mg & $222.6 \pm 38.4$ & $215.0 \pm 39.7$ & 0.171 \\
Incidence of failed sedation & $7 \%$ & $4 \%$ & 0.352 \\
VAS score & $2(1,3)$ & $2(1,2)$ & $0.001^{*}$ \\
Fatigue severity scores & $2.18 \pm 1.30$ & $3.66 \pm 0.87$ & $0.001^{*}$ \\
Postoperative grip strength, kg & $31.8 \pm 6.8$ & $35.5 \pm 7.7$ & $0.000^{*}$ \\
Incidence of nausea and vomiting & $7 \%$ & $11 \%$ & $0.014^{*}$ \\
Incidence of dizzness & $6 \%$ & $21.26 \pm 7.70$ & 0.205 \\
Recovery time, min & $24.03 \pm 7.80$ & $0.012^{*}$ \\
\hline
\end{tabular}

The VAS scores are the median (Q1, Q3). The Mann-Whitney U-test was used to evaluate the differences. Normally distributed statistics dates were mean \pm SD, and a two independent sample t-test was used to evaluate the differences. Ratios were compared by $X^{2}$ test.* $P<0.05$ 
their recovery [21]. Sufentanil is the classic analgesic drug used for painless GI endoscopy. However, during its clinical in our study, several patients experienced fatigue phenomenon lasting more than $1 \mathrm{~h}$. In $\mathrm{C}^{11}$ - labeled positron emission tomography, it was found that exercise can evoke and be related to changes in $\mu$ receptors in most of the limbic system, and deactivation of the $\mu$ receptor is the main reason for fatigue [22]. There was a strong correlation between grip strength and fatigue, after adjustment for age and height, that was independent of physical activity levels [23, 24]. Butorphanol resulted in less fatigue than sufentanil according to both subjective and objective indicators. We speculated that butorphanol can reduce visceral pain in GI endoscopy, as it targets the kappa receptor and decreases deactivation of the $\mu$ receptor, thereby reducing postoperative fatigue.

Compared with sufentanil, we believe that butorphanol, reduces postoperative nausea and vomiting, improves postoperative analgesia, and reduces postoperative fatigue, thus reducing the time at PACU after GI endoscopy.

This study had several limitations: (1) Fatigue is a multi-factor subjective experience. We only evaluated one objective indicator of fatigue, grip strength, and used a simplified scale. (2) Clinical examinations of outpatients were usually incomplete. The existence of hidden diseases and different sensitivities to drugs in individuals may have affected the results of the trial.

\section{Conclusion}

In summary, the $\mathrm{ED}_{95}$ for butorphanol in inhibiting body movement during painless GI endoscopy was $9.07 \mu \mathrm{g} / \mathrm{kg}$. Butorphanol combined with propofol as anesthesia for GI endoscopy reduced the recovery time, and, therefore, presents an excellent sedation strategy.

\section{Abbreviations}

ED95: Effective dose; Cl: Confidence intervals; Gl: Gastrointestinal; ASA: American Society of Anesthesiologists; BP: Blood pressure; ECG: Electrocardiogram; SpO2: Oxygen saturation; BIS: Bispectral index; PACU: Postanesthesia care unit

\section{Acknowledgments}

We thank all the patients, doctors, and nurses who participated in this study.

\section{Authors' contributions}

XZ Contribution: Design and conduct the study, analyze the data, and write the manuscript. LC Contribution: Write the manuscript and critical manuscript review. SZ Contribution: Design and conduct the study. LP: Design the study, analyze the data, and write the manuscript. All authors read and approved the final manuscript.

\section{Funding}

This work was supported by the Wenzhou Science and Technology Bureau Zhejiang, China (grant no: Y20190512), which covered the expense of electronic hand dynamometer and consumption of bispectral index sensor.

\section{Availability of data and materials}

The datasets during and analyzed during the current study are available from the corresponding author on reasonable requests.

\section{Ethics approval and consent to participate}

The Ethics Committee at the First Affiliated Hospital of Wenzhou Medical University approved this prospective trial, and the trial was registered at the Chinese Clinical Trial Registry (ChiCTR1900022780, 2019). Before study entry, all subjects reviewed and signed an informed consent document explaining the study procedures and potential risks.

\section{Consent for publication}

Not applicable.

\section{Competing interests}

Xiaona Zhu, Limei Chen, Shuang Zheng, and Linmin Pan declare no competing interests.

Received: 5 February 2020 Accepted: 27 April 2020

Published online: 02 May 2020

\section{References}

1. Chen W, Zheng R, Baade PD, Zhang S, Zeng H, Bray F, Jemal A, Yu XQ, He J Cancer statistics in China, 2015. CA Cancer J Clin. 2016;66(2):115-32.

2. Abraham NS, Fallone CA, Mayrand S, Huang J, Wieczorek P, Barkun AN. Sedation versus no sedation in the performance of diagnostic upper gastrointestinal endoscopy: a Canadian randomized controlled costoutcome study. Am J Gastroenterol. 2004;99(9):1692-9.

3. Altschuler SM, Escardo J, Lynn RB, Miselis RR. The central organization of the vagus nerve innervating the colon of the rat. Gastroenterology. 1993;104(2): 502-9.

4. Kivell B, Prisinzano TE. Kappa opioids and the modulation of pain Psychopharmacology. 2010;210(2):109-19.

5. Commiskey S, Fan LW, Ho IK, Rockhold RW. Butorphanol: effects of a prototypical agonist-antagonist analgesic on kappa-opioid receptors. $J$ Pharmacol Sci. 2005;98(2):109-16.

6. Horan PJ, Ho IK. Comparative pharmacological and biochemical studies between butorphanol and morphine. Pharmacol Biochem Behav. 1989;34(4): 847-54.

7. Garrity K, Jang A, Wagner S. Butorphanol use in laboring patients with preeclampsia or chronic hypertension. Pregnancy Hypertension. 2016;6(4): 288-90.

8. Wetchler BV, Alexander CD, Shariff MS, Gaudzels GM. A comparison of recovery in outpatients receiving fentanyl versus those receiving butorphanol. J Clin Anesth. 1989;1(5):339-43.

9. Zhang L, Shu R, Zhao Q, Li Y, Yu Y, Wang G. Preoperative butorphanol and flurbiprofen axetil therapy attenuates remifentanil-induced hyperalgesia after laparoscopic gynaecological surgery: a randomized double-blind controlled trial. Br J Anaesth. 2016;117(4):504-11.

10. Kong M, Yang L, Li J, Zhong Z, Cheng Y, Wu Z, Guo R. Low-dose butorphanol alleviates remifetanil-induced hyperalgesia in patients undergoing laparoscopic cholecystectomy. J Clin Anesth. 2016;34:41-5.

11. Borrat X, Valencia JF, Magrans R, Gimenez-Mila M, Mellado R, Sendino O, Perez M, Nunez M, Jospin M, Jensen EW, et al. Sedation-analgesia with propofol and remifentanil: concentrations required to avoid gag reflex in upper gastrointestinal endoscopy. Anesth Analg. 2015;121(1):90-6.

12. Dixon WJ. Staircase bioassay: the up-and-down method. Neurosci Biobehav Rev. 1991;15(1):47-50.

13. Hui MT, Subash S, Wang CY. The 50 and $95 \%$ effective doses of desflurane for removal of the classic laryngeal mask airway in spontaneously breathing anaesthetised adults. Anaesthesia. 2011;66(4):274-7.

14. Chen L, Zhou Y, Cai Y, Bao N, Xu X, Shi B. The ED95 of Nalbuphine in outpatient-induced abortion compared to equivalent Sufentanil. Basic Clin Pharmacol Toxicol. 2018;123(2):202-6.

15. Terkawi AS, Durieux ME, Gottschalk A, Brenin D, Tiouririne M. Effect of intravenous lidocaine on postoperative recovery of patients undergoing mastectomy: a double-blind, placebo-controlled randomized trial. Reg Anesth Pain Med. 2014;39(6):472-7.

16. Gorges M, Zhou G, Brant R, Ansermino JM. Sequential allocation trial design in anesthesia: an introduction to methods, modeling, and clinical applications. Paediatr Anaesth. 2017;27(3):240-7. 
17. Ozaki N, Sengupta JN, Gebhart GF. Differential effects of mu-, delta-, and kappa-opioid receptor agonists on mechanosensitive gastric vagal afferent fibers in the rat. J Neurophysiol. 2000;83(4):2209-16.

18. Ide S, Minami M, Ishihara K, Uhl GR, Satoh M, Sora I, Ikeda K. Abolished thermal and mechanical antinociception but retained visceral chemical antinociception induced by butorphanol in mu-opioid receptor knockout mice. Neuropharmacology. 2008;54(8):1182-8.

19. Gunther T, Dasgupta P, Mann A, Miess E, Kliewer A, Fritzwanker S, Steinborn R, Schulz S. Targeting multiple opioid receptors - improved analgesics with reduced side effects? Br J Pharmacol. 2018;175(14):2857-68.

20. Falt P, Liberda M, Smajstrla V, Kliment M, Bartkova A, Tvrdik J, Fojtik P, Urban O. Combination of water immersion and carbon dioxide insufflation for minimal sedation colonoscopy: a prospective, randomized, single-center trial. Eur J Gastroenterol Hepatol. 2012;24(8):971-7..

21. Salmon P. Hall GM. A theory of postoperative fatigue: an interaction of biological, psychological, and social processes. Pharmacol Biochem Behav. 1997:56(4):623-8.

22. Hiura M, Sakata M, Ishii K, Toyohara J, Oda K, Nariai T, Ishiwata K. Central mu-Opioidergic system activation evoked by heavy and severe-intensity cycling exercise in humans: a pilot study using positron emission tomography with 11C-Carfentanil. Int J Sports Med. 2017;38(1):19-26.

23. Strandkvist V, Andersson M, Backman H, Larsson A, Stridsman C, Lindberg A. Hand grip strength is associated with fatigue among men with COPD: epidemiological data from northern Sweden. Physiother Theory Pract. 2020; 36(3):408-16.

24. Goldblatt J, James OF, Jones DE. Grip strength and subjective fatigue in patients with primary biliary cirrhosis. Jama. 2001;285(17):2196-7.

\section{Publisher's Note}

Springer Nature remains neutral with regard to jurisdictional claims in published maps and institutional affiliations.

Ready to submit your research? Choose BMC and benefit from:

- fast, convenient online submission

- thorough peer review by experienced researchers in your field

- rapid publication on acceptance

- support for research data, including large and complex data types

- gold Open Access which fosters wider collaboration and increased citations

- maximum visibility for your research: over $100 \mathrm{M}$ website views per year

At $\mathrm{BMC}$, research is always in progress.

Learn more biomedcentral.com/submissions 